\title{
CORRECTION
}

\section{Correction to: Recent Bibliography on the Optimization of Multi-source Energy Systems}

\author{
Amina Gabour $^{1} \cdot$ Abderrezak Metatla $^{1} \cdot$ Ridha Kelaiaia $^{1}$ (D) $\cdot$ Farid Bourennani $^{2} \cdot$ Adlen Kerboua $^{1}$
}

Published online: 15 October 2019

(c) CIMNE, Barcelona, Spain 2019

\section{Correction to: \\ Archives of Computational Methods in Engineering \\ (2019) 26:809-830 \\ https://doi.org/10.1007/s11831-018-9271-6}

This correction has been initiated as author names were incorrectly indicated and should be read as:

GABOUR Amina instead of GAABOUR Amina.

Publisher's Note Springer Nature remains neutral with regard to jurisdictional claims in published maps and institutional affiliations.

The original article can be found online at https://doi.org/10.1007/ s11831-018-9271-6.

Ridha Kelaiaia

r.kelaiaia@univ-skikda.dz

Amina Gabour

a.gabour@univ-skikda.dz

Abderrezak Metatla

a.metatla@univ-skikda.dz

Farid Bourennani

fbourennani@uj.edu.sa

Adlen Kerboua

a.kerboua@univ-skikda.dz

1 LGMM Laboratory, Université 20 août 1955, Skikda, Algeria

2 Faculty of Computing and IT, University of Jeddah, Jeddah, Saudi Arabia 